\title{
Câncer e o microambiente tumoral
}

\section{Cancer and the tumor microenvironment}

\author{
Ana Cláudia Onuchic ${ }^{1}$, Roger Chammas²
}

\begin{abstract}
Onuchic AC, Chammas R. Câncer e o microambiente tumoral. Rev Med (São Paulo). 2010 jan.-mar.;89(1):21-31.

RESUMO: Antes tido como um conjunto de células alteradas em proliferação, hoje o câncer é mais bem entendido como um microambiente, em que as interações entre os elementos celulares e moleculares que o compõem são determinantes na progressão tumoral. Como resultado, a compreensão do evento neoplásico ganha complexidade crescente. A dinâmica das células tumorais passa a ser avaliada como parte de um verdadeiro tecido tumoral, sujeita a condições de vascularização, de oxigenação, de pressão intersticial e de necrose tecidual, que influenciam na cinética tumoral. Estão sendo identificados novos componentes deste nicho tumoral e as suas respectivas atuações. Entre esses integrantes, encontram-se os elementos da imunidade, cuja modulação tem sido demonstrada por uma série de pesquisas aqui revisadas, tanto no sentido da vigilância imunológica, como pressão seletiva negativa, quanto no favorecimento da progressão tumoral. Esta revisão analisará a neoplasia do ponto de vista de um microambiente tumoral, focando na participação imunológica e na cinética tumoral, expondo as principais idéias e descobertas que criaram e estão aperfeiçoando o conceito de câncer.
\end{abstract}

DESCRITORES: Neoplasias/imunologia; Neoplasias/genética; Inflamação; Vigilância imunológica; Macrófagos; Carga tumoral/imunologia.

\section{INTRODUÇÃO}

$\mathrm{N}$ o modelo atual da oncogênese, o câncer surge a partir de células que sofrem uma seqüência de mutações ou alterações genéticas. Tais alterações podem ser resultados de uma variedade de fatores, tanto intrínsecos, como mutações genéticas herdadas ou erros aleatórios na replicação do DNA, quanto extrínsecos, por exemplo: dano e instabilidade genética induzida por radiação, por substâncias químicas ou por infecção viral. Uma única mutação, no entanto, dificilmente leva à formação de um tumor; para que esse processo ocorra, são necessárias duas a seis (ou mais) modificações genéticas, que irão progressivamente interferir nos mecanismos responsáveis por proliferação, diferenciação e morte celular ${ }^{19,30}$.

\footnotetext{
${ }^{1}$ Acadêmica do $5^{\circ}$ ano da Faculdade de Medicina da Universidade de São Paulo.

2 Professor titular de Oncologia, Departamento de Radiologia da Faculdade de Medicina da Universidade de São Paulo. Endereço para correspondência: Ana Cláudia Onuchic. Av. Dr. Arnaldo, 455 - $4^{\circ}$ andar, sala 4122 - São Paulo, SP. CEP: 01246-903
} 
Em sua importante revisão, Hanahan e Weinberg ${ }^{14}$ propuseram seis alterações fundamentais na fisiologia celular que governariam a transformação de uma célula normal em cancerígena: autosuficiência em sinais de proliferação, insensibilidade a sinais inibidores de crescimento, evasão da apoptose, potencial replicativo ilimitado, angiogênese sustentada, e invasão tecidual e metástase (Figura 1). Cada uma dessas "capacidades", possíveis de serem alcançadas através de diferentes mecanismos moleculares, representaria a superação de distintas estratégias, intrínsecas às células e aos tecidos, contra o desenvolvimento tumoral, e o acúmulo de tais alterações contribuiria à crescente malignidade do câncer.

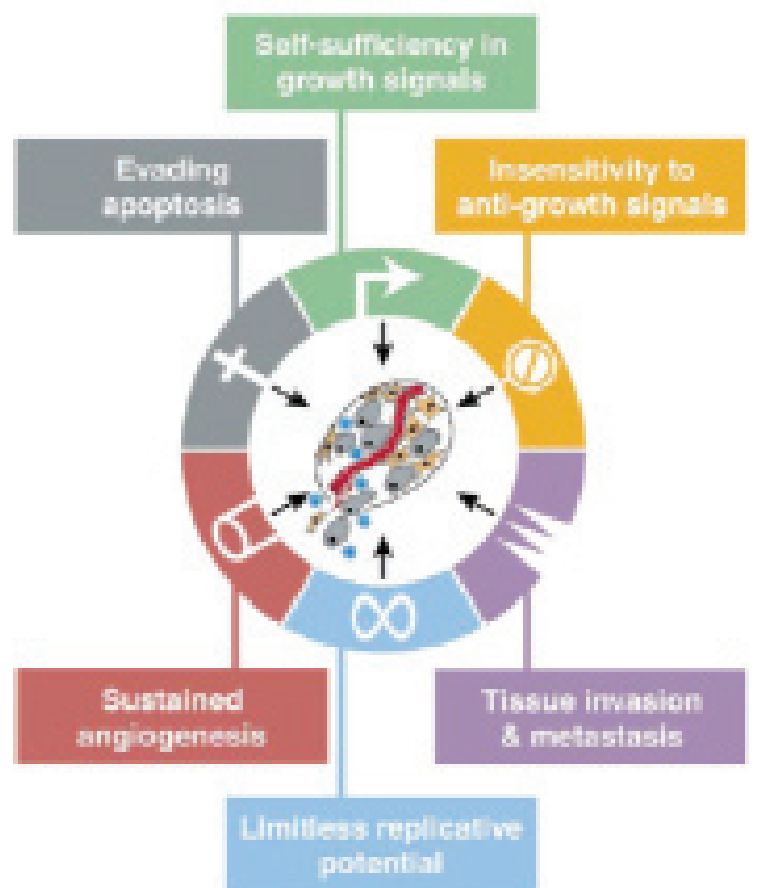

Figura 1. As seis alterações fundamentais que levam à malignidade (p.58) $)^{14}$

Apesar de os distúrbios genéticos iniciais ocorrerem nas células propriamente cancerígenas, a análise tumoral que se limita a essas células - constituindo uma visão reducionista - vem se mostrando cada vez mais incompleta. Atualmente, a percepção do câncer como um microambiente tumoral, onde interagem células geneticamente alteradas, células normais (como fibroblastos, células imunes, células endoteliais), vasos, e substâncias produzidas localmente ou provenientes da irrigação sanguínea, tem se mostrado muito mais satisfatória na compreensão do desenvolvimento tumoral ${ }^{14}$.

De fato, estudos recentes mostram que células não-cancerígenas têm participação significativa em diversos processos de progressão tumoral, tais como angiogênese, metástase ${ }^{6}$ e proliferação celular ${ }^{7}$. Dessa forma, o tumor pode ser visto como um tecido complexo, com distorção da homeostasia tecidual original, e em que células "normais" são cooptadas a funcionar de acordo com essa nova dinâmica tecidual, ditada principalmente pelas células cancerígenas.

A identificação da participação dessas demais células na progressão tumoral está abrindo caminho para a pesquisa e para o desenvolvimento de novas possibilidades terapêuticas, tendo como alvo tais células "normais" (não-cancerígenas) do microambiente tumoral, que frequentemente não apresentam taxas de proliferação desreguladas ou instabilidade genética aumentada ${ }^{1,11}$.

\section{IMUNIDADE E CÂNCER}

Dentre as demais células do microambiente tumoral, estudos recentes vêm demonstrando uma importância crescente da atuação de células do sistema imune e seus produtos no tecido neoplásico. Características do infiltrado inflamatório que adentra o tumor interferem no desenvolvimento e progressão do mesmo, e isso começa a indicar que não só o câncer constitui um microambiente, mas que ainda estaria inserido em um macroambiente - o organismo - no qual têm origem as células imunes que irão migrar até o tumor e passar a compor seu estroma, influenciando dessa forma em seu curso ${ }^{5,6,7}$.

Uma série de pesquisas revelou uma importante associação entre inflamação e câncer, mostrando que inflamação crônica é um dos fatores epigenéticos que mais contribuem ao surgimento e à progressão do tumor, fato primeiro observado por Virchow em 1858. De fato, indivíduos com colite crônica ulcerativa têm uma chance 10 vezes maior de desenvolver carcinoma colorretal, enquanto pacientes com hepatite crônica ou cirrose têm maior risco de apresentar carcinoma hepatocelular. O mesmo é observado na bronquite crônica e no câncer de pulmão, entre inúmeros outros exemplos. Demonstrou-se, por outro lado, que o uso crônico de agentes antiinflamatórios não-esteroidais reduz a formação tumoral2,5,8.

Atualmente, são concebidos dois momentos de atuação do sistema imune: previamente à existência da célula tumoral (contribuindo precisamente para esta transformação de normal a cancerígena) e, posteriormente, durante a instalação e progressão do tumor, incorporado ao microambiente tumoral. Há várias teorias que explicam o primeiro momento, ou seja, o porquê de células tumorais surgirem em locais caracterizados por intensa presença de células imunes, como em sítios de inflamação 
crônica. Entre as principais explicações propostas, estão: a regeneração tecidual contínua encontrada na resposta inflamatória, levando a uma maior chance de ocorrência de mutações, e então de proliferação dessas células mutadas; a criação de uma microrregião mutagênica, através da produção de espécies reativas de oxigênio e nitrogênio pelas células imunes recrutadas; e promoção de angiogênese (neovascularização), classicamente presente em processos inflamatórios, e já descrita como uma alteração fundamental para o desenvolvimento tumoral. Estes mecanismos, relacionados diretamente à inflamação, contribuem para o surgimento de malignidade nas células mais próximas $^{6,21}$.

\section{VIGILÂNCIA IMUNOLÓGICA}

Historicamente, o sistema imune foi primeiramente descrito como um mecanismo de eliminação de células tumorais (segundo momento). O conceito de "immunosurveillance", ou seja, de vigilância imunológica, consolidado em meados do século passado, defende que o sistema imune é capaz de reconhecer e eliminar tumores em desenvolvimento, podendo assim evitar o surgimento de tumores clinicamente aparentes, mesmo na ausência de intervenção terapêutica. Com o desenvolvimento de novas tecnologias científicas, tais como modelos animais, anticorpos específicos e mutações gênicas dirigidas, foi possível investigar experimentalmente a existência da vigilância imunológica ${ }^{9,34}$.

Os primeiros experimentos com camundongos atímicos "nude" (modelo de imunodeficiência) mostraram não haver diferença entre o desenvolvimento tumoral nesses animais e em camundongos selvagens, refutando, a princípio, a eficácia do sistema imune em impedir a formação tumoral ${ }^{29}$. Posteriormente, entretanto, constatou-se que o camundongo "nude" era um modelo imperfeito de imunodeficiência, e novos estudos começaram a desvendar mecanismos moleculares de vigilância imunológica, envolvendo principalmente IFN- $\gamma$, perforina e linfócitos. Observou-se que a produção endógena de IFN- $\gamma$ protegia o animal tanto do crescimento de tumores transplantados quanto do desenvolvimento de tumores espontâneos e quimicamente induzidos. De forma complementar, animais tratados com anticorpos específicos contra IFN- $\gamma$ apresentaram crescimento mais acelerado de fibrossarcomas transplantados. A perforina, presente em células T citotóxicas e NK, está envolvida na morte celular mediada por linfócitos. Camundongos $\mathrm{pfp}^{-/}$, que não expressam a perforina, são mais suscetíveis à formação de tumores espontâneos e induzidos do que animais que expressam tal molécula normalmente. Por fim, a importância dos linfócitos na vigilância imunológica foi demonstrada através de estudos com modelos animais que não expressam RAG-2, proteína envolvida no rearranjo de receptores linfocíticos. Esses animais, portanto, não possuem células $B, T$ ou NKT, formando tumores epiteliais espontâneos em maior grau do que em animais geneticamente semelhantes, porém normais para expressão de RAG-2 ${ }^{9,10,26}$.

Evidências da atuação da vigilância imunológica também foram encontradas em humanos. Pacientes com gamopatia monoclonal, uma condição pré-maligna de células $B$, apresentam intensa resposta imunológica de linfócitos $\mathrm{T}$. Além disso, pacientes com síndrome de Chediak-Higashi, que apresentam função anormal de células NK, possuem uma chance 200 vezes maior de desenvolver câncer que a população normal. A presença de células $T$ infiltrativas nos tumores estabelecidos pode ser utilizada como marcador de prognóstico, estando relacionado a menor invasão metastática do tumor e maior sobrevida do paciente ${ }^{9,34}$.

\section{IMUNOEDIÇÃO}

Apesar das evidências a favor do papel fundamental do sistema imunológico no combate à formação tumoral, o surgimento de câncer ocorre também em pessoas e animais com o sistema imune preservado. De fato, ao aprofundar os estudos na interface imunidade/neoplasia, descobriu-se que o sistema imune não atua somente na eliminação de células tumorais, mas também pode agir selecionando ou "editando" os tumores emergentes. Esse conceito refinado da vigilância imunológica foi chamado de edição imunológica ou imunoedição. Dunn e Schreiber ${ }^{9}$, ao reconhecer essa nova teoria, propõem que a imunoedição seja composta por três fases: eliminação, equilíbrio e escape, conhecidos como os três "Es" da imunoedição (Figura 2).

A fase da eliminação, em que células malignas ou pré-malignas são reconhecidas e destruídas pelo sistema imunológico, constitui a teoria original da vigilância imunológica. A segunda fase representa um equilíbrio dinâmico, muitas vezes capaz de durar até anos, em que elementos do sistema imune, atuando contra as células tumorais, são capazes de controlá-las, porém não de eliminálas completamente. Dessa forma, há uma resposta imune que exerce pressão seletiva num conjunto de células neoplásicas instáveis e continuamente sujeitas a mutação. O resultado é uma seleção 
"darwiniana", em que sobrevivem e replicam-se células tumorais mais resistentes à atuação imune, com reduzida imunogenicidade, formando uma nova população clonal no tumor. Esse processo é também denominado "imunosseleção"34. Quando os clones tumorais resistentes são selecionados de forma a poderem crescer independentemente de uma resposta imunológica normal e competente, atingese a fase do escape, em que as células neoplásicas "escapam" do controle imunológico. Esse processo é tão importante na tumorigênese que, em 2004, Schreiber e seu grupo introduziram a evasão da vigilância imunológica (o "escape" tumoral) como uma sétima característica fundamental do câncer (em referência à revisão de Hanahan e Weinberg $\left.{ }^{14}\right)^{9,34}$.

Recentemente, tal conceito vem-se ampliando: ao investigar como as células tumorais conseguem se esquivar do sistema imune, novas pesquisas estão descobrindo que não apenas essas células são capazes de suprimir a resposta imune anti-tumoral, mas também têm a interessante capacidade de utilizar a presença do infiltrado inflamatório tumoral em seu favor. Tal processo tem sido descrito como

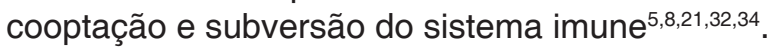

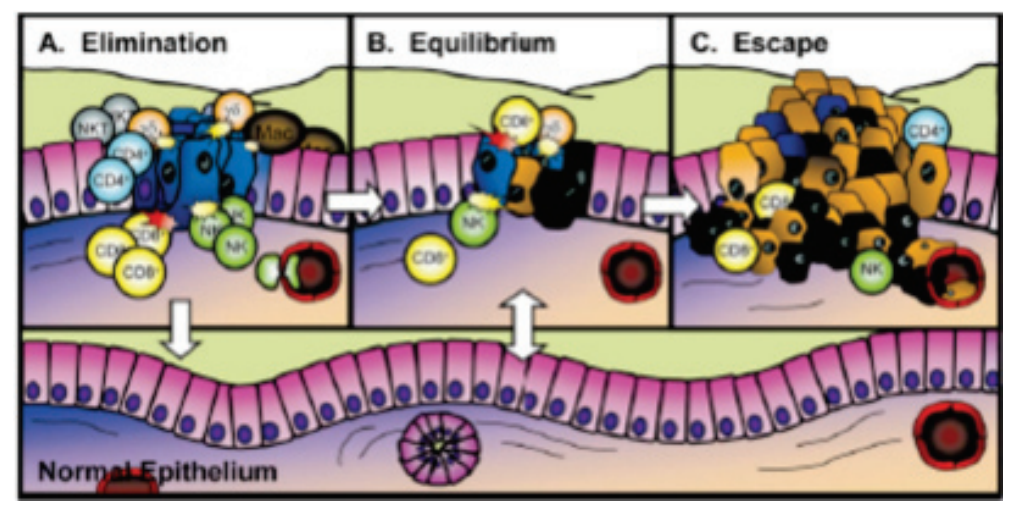

Figura 2. As três fases da imunoedição: A. eliminação; B. equilíbrio; C. escape (p.C-1) ${ }^{9}$

\section{SISTEMA IMUNE COOPTADO E PROGRESSÃO TUMORAL}

Experimentos recentes mostram que as células do sistema imune atuam na remodelação tecidual, assim contribuindo para crescimento tumoral, metástase e tolerância imune. As células imunes que integram o microambiente tumoral sofrem um verdadeiro processo de cooptação pelas células tumorigênicas, contribuindo à angiogênese, limpeza tecidual e proliferação celular. Foram descritos três estágios dessa "educação" das células imunes pelas células tumorais: 1) recrutamento das células imunes via produção de citocinas (proteína quimiotática de monócitos-1 [MCP-1] e interleucina-8 [IL-8]); 2) educação/cooptação via secreção de citocinas que regulam diferenciação de células imunes no sentido de promover o tumor (IL-6, fator de necrose tumoral- $\alpha$ [TNF- $\alpha$ ] e fator inibitório da migração de macrófagos [MIF]); 3) resposta imune, em que células imunes diferenciadas geram citocinas, hormônios e fatores de crescimento, agentes promotores de proliferação tumoral e tolerância imune ao tumor ${ }^{5,8,32}$.

De fato, mostrou-se que células tumorais são capazes de regular sua expressão de citocinas, quimiocinas e outros mediadores para favorecer o recrutamento de células imunes circulantes e, pos- teriormente, para contribuir à progressão neoplásica Observou-se que alguns dos oncogenes ativados mais frequentemente encontrados em tumores, como o fator de transcrição MYC, a tirosina-quinase RET, ou genes da família RAS, podem promover um programa de transcrição que resulta na expressão de mediadores inflamatórios contributórios à progressão tumoral. Exemplos desses mediadores incluem CCL2 e CCL20, quimiocinas que atraem monócitos e células dendríticas; citocinas pró-inflamatórias como IL-1 $\beta$ e ciclooxigenase 2 (COX2); e fatores pró-angiogênicos como IL-18. As células tumorais podem ainda empregar moléculas de adesão, quimiocinas e receptores envolvidos na migração de células inflamatórias para facilitar o processo de metástase. Foi demonstrado que animais deficientes nos receptores de adesão E- e P-selectina têm um menor índice de metástases pulmonares por células de melanoma que expressam sialyl-Lewis X (um carboidrato reconhecido pelas selectinas) do que animais normais ${ }^{2,8,21}$.

Algumas vias de sinalização relacionadas à inflamação e envolvidas no desenvolvimento tumoral já foram bem descritas, tais como a via do STAT3 (signal transducer and activator of transcription, ou transdutor de sinal e ativador de transcrição 3) e a via do NF-kB (nuclear factor-kB, ou complexo fator nuclear kB). O STAT3 é um fator de transcrição que pode 
ser ativado por IL-6, EGF (epidermal growth factor, fator de crescimento epidérmico) e VEGF (vascular endothelial growth factor, fator de crescimento vascular endotelial), entre outros. A atividade do STAT3 promove a sobrevivência de células tumorais pelo aumento da proteína anti-apoptótica Bcl-xL, descrito em células de mieloma múltiplo, além de promover a síntese de citocinas e fatores de crescimento que impedem a maturação de células dendríticas, comprometendo a atividade anti-tumoral de células T CD8 e células $\mathrm{NK}^{2,18}$.

NF-kB é o principal ativador da resposta imune e inflamação, e sua estimulação aumenta a expressão de citocinas pró-inflamatórias, quimiocinas, fatores de crescimento, metaloproteinases, moléculas de adesão e proteínas anti-apoptóticas. Evidências indicam que a ativação constitutiva de NF-kB é encontrada em grande parte de linhagens celulares e tecidos tumorais ${ }^{5}$. NF-kB é ativado principalmente pela via dos receptores Toll-like (TLR), tendo como intermediário a proteína MyD88. Os TLRs são receptores de membrana que reconhecem padrões moleculares conservados de origem microbiana, conhecidos como PAMPs (pathogen-associated molecular patterns). Tais padrões incluem LPS, ácido lipoteicóico, e RNA de simples ou dupla fita. Além dos ligantes microbianos, os TLRs também são capazes de reconhecer ligantes endógenos, especialmente TLR2 e TLR4, como as heat shock proteins (HSP), high mobility group box 1 (HMGB1, uma citocina pró-inflamatória) e fibronectina (presente na matriz extracelular), entre outros (25). A participação da via TLR-NF-kB na progressão tumoral foi demonstrada nos últimos anos. Observou-se que a administração sistêmica de LPS, ligante de TLR, aumenta a migração, invasão e angiogênese de sítios secundários de células metastáticas de adenocarcinoma de mama. Além disso, camundongos deficientes em TLR4 mostram uma incidência reduzida de tumores colorretais em comparação a camundongos normais ${ }^{2,5,18,25}$.

\section{MACRÓFAGOS}

Entre as células componentes do sistema imune que infiltram o tumor, a participação de macrófagos vem ganhando importância e complexidade crescentes. Macrófagos são envolvidos em processos de inflamação crônica e parecem estar associados à progressão tumoral e metástase. Densidades elevadas de macrófagos no tecido neoplásico foram relacionadas a mau prognóstico em mais de $80 \%$ de estudos publicados, e a superexpressão de CSF-1 (colony-stimulating factor -1 , um fator de crescimento de macrófagos), já encontrada em tumores de mama, útero, e ovário, está correlacionada a um alto grau neoplásico e pior prognóstico. Um estudo muito interessante, realizado em camundongos que não expressam CSF-1, mostrou que a ausência deste fator não afetou a formação dos tumores mamários murinos primários, porém atrasou tanto o recrutamento de macrófagos para o tumor como sua progressão para malignidade e metástase para o pulmão6,17.

Em tecidos em desenvolvimento ou em reparo, os macrófagos exercem papéis fundamentais, estando envolvidos na remodelação de matriz extracelular, retirada de células apoptóticas, migração epitelial e angiogênese. No tecido tumoral, onde recebem o nome de "macrófagos associados ao tumor" (TAM - tumor-associated macrophages), os macrófagos são recrutados e cooptados pelas células alteradas, sofrendo uma diminuição de sua função imune e uma exacerbação de sua função trófica. Condeelis e Pollard ${ }^{6}$ propõem como principais características que levariam os macrófagos a contribuir à progressão tumoral: inflamação, remodelação de matriz, angiogênese, disseminação, intravasamento, e invasão das células tumorais.

Uma das principais evidências da participação dos macrófagos na progressão tumoral foi a descoberta de uma interação parácrina entre os mesmos e as células tumorais. Macrófagos perivasculares secretam EGF, captado pela célula tumoral, que expressa receptor de EGF (EGFR), e assim realiza a quimiotaxia até o vaso sanguíneo. As células neoplásicas então secretam CSF-1, que atrai macrófagos e os estimula a produzir mais EGF, completando um círculo parácrino. A sinalização entre as células também afeta a atividade de WASP e N-WASP, reguladores de actina, resultando na formação de podossomos nos macrófagos e de processos invasores nas células tumorais, com consequente intravasamento das células neoplásicas (Figura 3$)^{6,33}$.

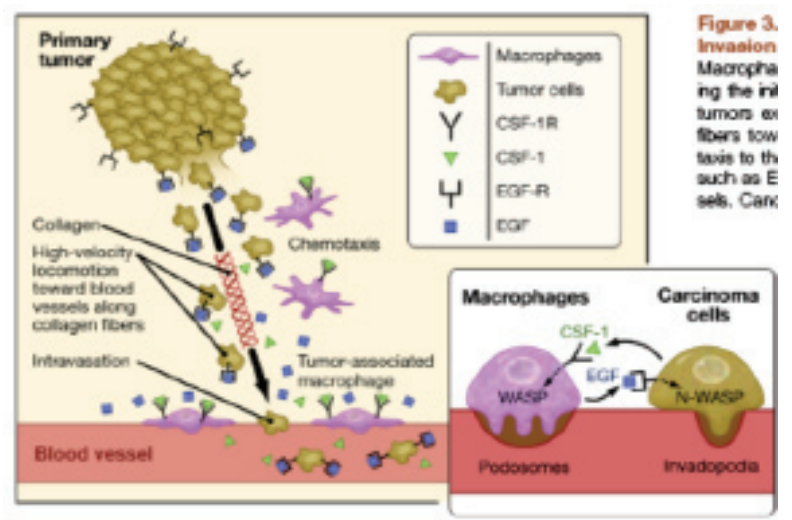

Figura 3. Esquema da interação parácrina entre as células tumorais e macrófagos envolvendo CSF-1 e EGF (p. 265) ${ }^{6}$

Recentemente, foi possível obter uma visualização direta da atuação dos macrófagos. 
Usando uma técnica conhecida como microscopia multi-fóton, mostrou-se que, em um modelo de câncer de mama murino, o intravasamento da grande maioria das células tumorais ocorre em associação com macrófagos perivasculares ${ }^{33}$.

É importante notar, entretanto, que os macrófagos não formam uma população homogênea. Monócitos são recrutados da circulação e adentram o tecido, onde se diferenciam em macrófagos com fenótipos distintos, de acordo com fatores presentes no local. Há classicamente dois grupos de macrófagos, diferenciados de acordo com seu modo de ativação, receptores e citocinas produzidas: M1 e M2. Os macrófagos do tipo M1 são ativados por produtos microbianos ou IFN- $\gamma$, produzem citocinas pró-inflamatórias, como IL-12, IL-23, IFN- $\gamma$, IL18 , TNF- $\alpha$ e atuam na resposta contra patógenos (especialmente parasitas intracelulares) e células tumorais. Os macrófagos do tipo M2, por sua vez, são ativados por citocinas como IL-4, IL-10 e IL13, possuem receptores de manose e galactose, e produzem VEGF, IL-6, IL-10, PG, iNOS, IDO, agindo no reparo tecidual, remodelação, e angiogênese, contribuindo potencialmente à progressão tumoral. Recentemente, o grupo M2 foi subdividido de acordo com seu modo de ativação em M2a, ativado por exposição a IL-4 e IL-13; M2b, induzido por exposição combinada a imunocomplexos e agonistas de TLR ou receptor de IL-1; e M2c, ativado por IL-10. Os dois primeiros estão mais relacionados a funções de regulação imune, enquanto o último age mais na supressão da resposta imunológica e na remodelação tecidual ${ }^{5,13,20,27}$.

Um estudo recente demonstrou a importância dos macrófagos M2 no favorecimento metastático tumoral. Camundongos knockout para CD1 não desenvolvem células NKT, as principais produtoras de IL-13. Tais animais apresentam polarização defeituosa dos macrófagos para o fenótipo M2. Esses animais rejeitam tumor metastático de mama murino e sobrevivem indefinidamente se for efetuada remoção cirúrgica do sítio tumoral primário. Tais pesquisadores mostraram que a resposta foi resultado de três fatores principais: a geração de macrófagos M1 tumoricidas, a redução de células $\mathrm{Gr} 1{ }^{+} \mathrm{CD} 11 \mathrm{~b}{ }^{+}$supressoras mielóides e a produção de linfócitos ativados ${ }^{27}$.

\section{ALTERAÇÕES NO MICROAMBIENTE E RESPOS- TA IMUNE INDUZIDA}

Alterações são frequentes no microambiente tumoral e podem afetar de forma importante a resposta imune no interior do tumor. Uma pesquisa recente evidencia uma forte influência da presença de células apoptóticas no microambiente tumoral, modulando a progressão do câncer. Duas linhagens celulares murinas de melanoma, Tm1 e Tm5, são invariavelmente tumorigênicas em doses maiores que $10^{4}$ células, enquanto doses de $10^{3}$ células ou menos raramente resultam no desenvolvimento de um tumor. No entanto, demonstrou-se que uma dose subtumorigênica de células cancerígenas $\left(10^{3}\right)$, injetada conjuntamente com células apoptóticas, permite o desenvolvimento das células tumorais, com a formação de uma massa tumoral. Formula-se que a importância da co-inoculação de células apoptóticas, e não necróticas, esteja no infiltrado inflamatório transiente gerado, caracterizado pela grande presença de macrófagos e neutrófilos ${ }^{7}$.

Realmente, evidências desse mesmo estudo mostram que o implante de células tumorigênicas em camundongos deficientes em receptor de bradicinina subtipo 1 (BK1-R) não foi positivamente regulado pela co-injeção de células apoptóticas. A bradicinina possui um importante papel na resposta imune, regulando principalmente a migração de neutrófilos para o sítio de inflamação ${ }^{7}$. Além disso, a ausência de BK1-R nos neutrófilos pode estar relacionada à não-indução da apoptose, fundamental para a conclusão de processos inflamatórios ${ }^{22}$. A ativação do BK1-R ainda contribui à resposta inflamatória com a produção de citocinas (IL-1 $\beta$, TNF- $\alpha$ ), e a sua estimulação em macrófagos leva à síntese de IL-1 e TNF. De forma complementar, outro estudo mostrou que animais deficientes em receptor de IL-1 apresentam uma resposta inflamatória neutrofílica reduzida a estímulos como presença de células mortas e lesão tecidual, evidenciando o papel de IL-1 como um dos principais mediadores responsáveis pela geração do infiltrado inflamatório neutrofílico ${ }^{4}$.

A necrose é um fenômeno frequente em tumores, podendo estar associado a uma intervenção terapêutica ou ao próprio crescimento da massa tumoral. Ao contrário do esperado, a presença de necrose no tumor, entretanto, pode estar associada a mau prognóstico. Os centros necróticos representam a origem do infiltrado inflamatório no tumor e muitos fatores celulares liberados pelas células necróticas podem atuar como estímulos intensos para migração e diferenciação de células imunes, especialmente macrófagos ${ }^{5}$.

\section{CINÉTICA CELULAR EM TUMORES}

Em tecidos normais, é reconhecida a existência de um controle homeostático tecidual 
intrínseco, o qual garante o equilíbrio entre a regeneração e a morte celular dentro deste mesmo tecido - mantendo dessa forma seu tamanho e sua composição constante. Nos tecidos tumorais, por sua vez, ocorre uma quebra dos mecanismos homeostáticos, resultando num desbalanço entre proliferação e morte celular e consequentemente num aumento da população e tamanho tumoral.

Através da autorradiografia e, mais recentemente, da citometria de fluxo, tornou-se possível avaliar a cinética tumoral. A citometria de fluxo baseia-se na análise de cada célula de uma suspensão do tumor. Pode-se avaliar o conteúdo de DNA de cada célula, através da administração de marcadores fluorescentes (por exemplo, iodeto de propídio) que se combinam ao conteúdo de DNA da célula, sendo a fluorescência posteriormente lida pelo citômetro. De forma semelhante, pode-se observar o ritmo de proliferação celular através da administração de bromodeoxiuridina (BrdU), que é incorporada na síntese de novo DNA ${ }^{23}$

Chama-se "fração de crescimento" (growth fraction) a proporção de células dentro de um tumor que estão em atividade proliferativa. É importante reconhecer que uma considerável parte das células tumorais não está replicando, e também que a fração de crescimento não corresponde por si só ao crescimento tumoral. A taxa de crescimento de um tumor também depende de morte (e.g., necrose, apoptose) e perda (e.g., metástase ou disseminação local) celular, representando um balanço entre esses e a proliferação celular ${ }^{30}$

Entretanto, estudos demonstram que taxas de replicação celular são bastante heterogêneas em diferentes regiões do tumor. Tal achado pode ser em parte explicado por diferentes taxas de diferenciação celular, uma vez que esta é inversamente relacionada à taxa de proliferação. Outro fator corresponde à existência de diferentes subpopulações celulares dentro do mesmo tumor, resultado de alterações genéticas adicionais ao longo da progressão tumoral. Por fim, e possivelmente mais importante, há a disponibilidade desigual de oxigênio e demais nutrientes para regiões distintas do tumor, resultando na ocorrência bastante frequente de locais de hipóxia e/ou necrose dentro de tumores sólidos ${ }^{30}$.

\section{REPOPULAÇÃO TUMORAL}

O conceito de repopulação tumoral refere-se à proliferação das células tumorais, sobreviventes de processos nocivos direcionados ao tumor tais como quimioterapia, radioterapia, substâncias anti-angiogênicas, ou mesmo um desequilíbrio interno; representa um problema importante nos casos de tratamento de tumores. A fim de permitir a recuperação das demais células do paciente, o tratamento quimioterápico ou radioterápico deve ser espaçado. Contudo, essa estratégia, ao mesmo tempo em que preserva territórios não tumorais, tem como efeito colateral a concomitante repopulação da massa tumoral por células tumorais progressivamente mais resistentes a tratamento ${ }^{3,16}$.

Os mecanismos que contribuem à repopulação do tumor estão muito ligados a conceitos de cinética tumoral. $\mathrm{O}$ modo e a intensidade com que um agente anti-tumoral (e.g., quimioterápico) é capaz de atuar em diferentes regiões tumorais (perivasculares, hipóxicas) e tipos celulares (célulastronco tumorais, células hipóxicas, entre outros) são determinantes no processo de repopulação tumoral que se realiza em seguida.

Em primeiro lugar, observa-se, na grande maioria dos tumores, um aumento da pressão intersticial tumoral, devido a fatores como a elevada permeabilidade dos vasos tumorais e vasos linfáticos pouco funcionais ou ausentes, que causam um aumento na pressão intravascular local. Já de início, a pressão intratumoral elevada dificulta a penetração de um agente quimioterápico no tumor sólido. Ademais, como o quimioterápico atinge o tumor pela corrente sanguínea, a sua entrada e atuação no mesmo são altamente dependentes da quantidade, qualidade e permeabilidade da vascularização tumoral, enfatizando o papel da angiogênese e dos neovasos nos efeitos observados, principalmente em tumores maiores $^{12,31}$

Os Gráficos 4A, B, C ${ }^{31}$ caracterizam a variação do microambiente tumoral de acordo com a distância ao vaso sanguíneo mais próximo. O gráfico A ilustra a queda da pressão de oxigênio a partir do vaso, indicando o início da zona de hipóxia a partir de aproximadamente $80 \mu \mathrm{m}$. Também se observa a diminuição do $\mathrm{pH}$, resultado da decrescente $\mathrm{pO}_{2}$ e resultante aumento da glicólise nas células hipóxicas, que assim geram lactato; a isso ainda se soma a perfusão irregular do tumor, o que causa um "clearance" diminuído de metabólitos ácidos. O gráfico B ilustra o perfil de distribuição heterogênea do quimioterápico doxorubicina, que também diminui em função do aumento da distância ao capilar. O gráfico C mostra que a distribuição heterogênea da droga resulta numa mortalidade celular igualmente heterogênea, com maior morte celular próxima ao vaso, porém crescente sobrevivência em regiões cada vez mais distantes, acarretando uma sobrevivência tumoral total maior (barras brancas) do que o esperado numa distribuição homogênea da droga (barras pretas). 

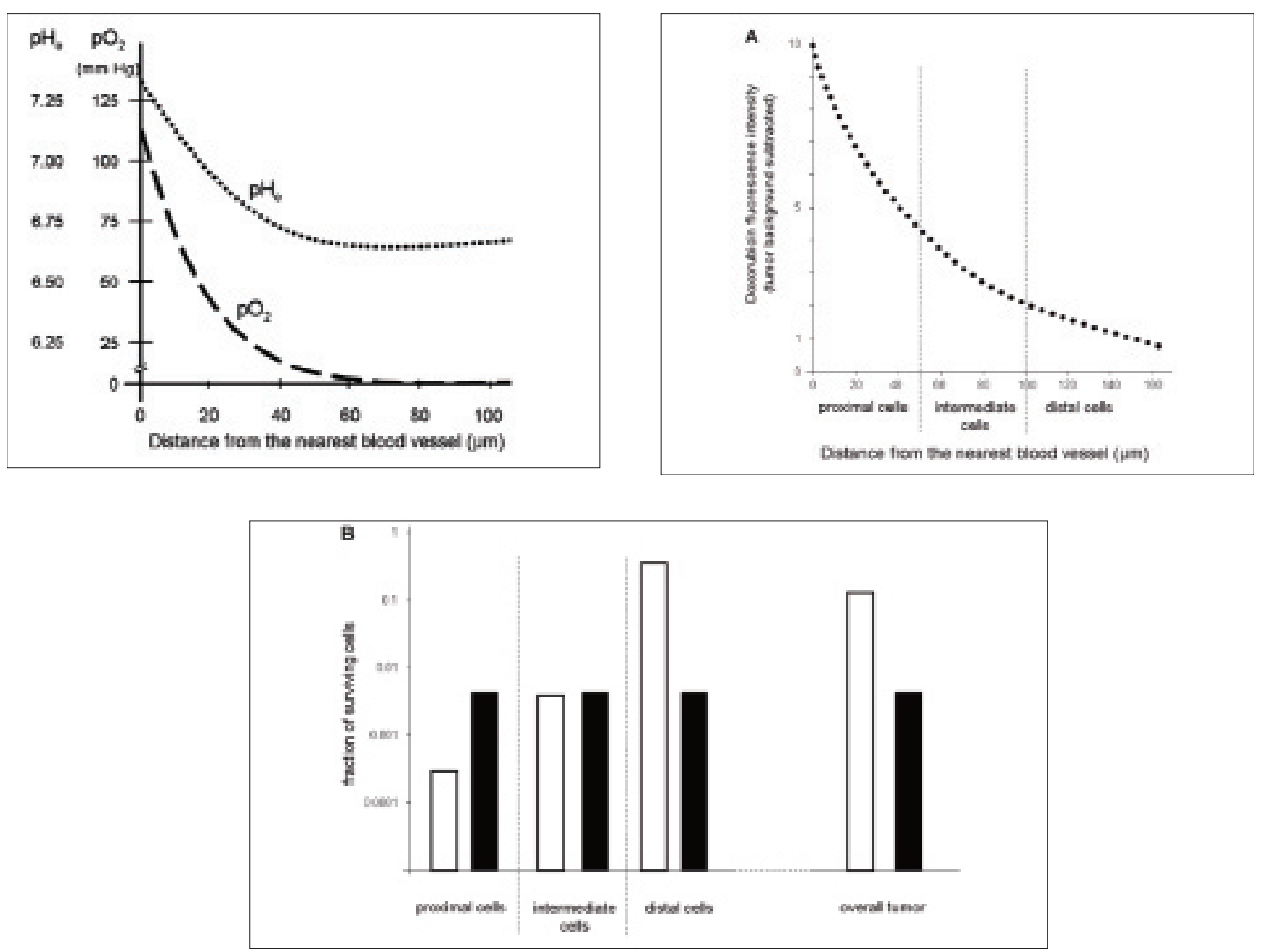

Figura 4. A: Gradiente de concentração de oxigênio e de pH em relação à distância ao capilar. B: Intensidade de fluorescência de doxorubicina em relação à distância ao capilar. C: Fração de células sobreviventes para populações celulares a diferentes distâncias do capilar (p.1442, 1448) $)^{31}$

A partir do vaso sanguíneo, o oxigênio e os nutrientes, assim como o quimioterápico, dependem da difusão para atingir as células que compõem o tecido tumoral. A vascularização irregular e limitada da grande maioria dos tumores faz com que existam células muito distantes de qualquer capilar, estando, portanto, em deprivação de nutrientes e em hipóxia crônica. Essa situação pode levar à necrose das células, porém a maioria das células hipóxicas são ainda viáveis. Com efeito, após a morte das células localizadas próximas aos vasos - portanto em maior contato com o quimioterápico -, o aporte de nutrientes e oxigênio às células hipóxicas mais próximas melhora consideravelmente, permitindo que estas células sobrevivam e contribuam à repopulação tumoral ${ }^{15,24,31}$.

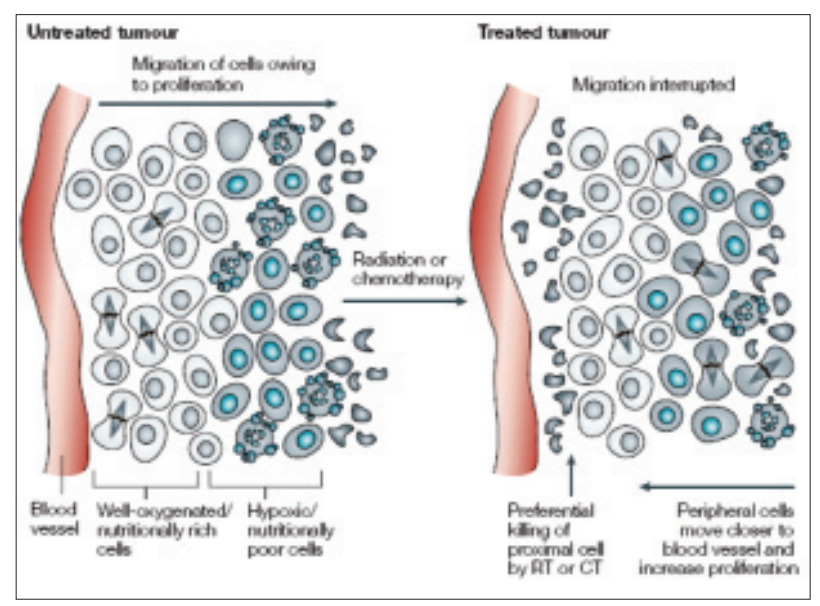

Figura 5. Esquema comparando a cinética celular em um tumor não-tratado (esquerda) com um tumor tratado com radio- ou quimioterapia (direita) (p. 521) ${ }^{16}$ 
Um estudo realizado por Petersen et al. ${ }^{23}$ avaliou as alterações no microambiente de carcinomas escamosos FaDu humanos, implantados em camundongos nude, sujeitos a radioterapia fracionada. Observou-se que a marcação com BrdU e Ki67 (marcadores de proliferação celular) durante a parte inicial da radioterapia era em média mais baixa que em tumores controle, não-tratados. No entanto, posteriormente no decorrer do tratamento, o índice de proliferação se tornou significativamente maior nos tumores tratados, com a marcação de replicação celular se concentrando em células próximas aos capilares tumorais. Experimentos adicionais mostraram que havia uma grande quantidade de células tumorais hipóxicas durante a parte inicial da radioterapia, seguida de uma melhora significativa da oxigenação tumoral, coincidente com o aumento do índice de proliferação celular observado. Os pesquisadores propõem que, inicialmente, há uma morte das células próximas aos capilares, que, mais oxigenadas, são mais sensíveis à radioterapia. As células hipóxicas, menos sensíveis, sobrevivem, e com a morte das células próximas aos vasos, ficam sujeitas a uma melhor oxigenação, sendo recrutadas novamente ao ciclo celular. Esse estudo indica que a cinética de repopulação do tumor em questão, em resposta à radioterapia fracionada, é determinada não apenas por processos intracelulares, mas também por uma complexa interação com um microambiente alterado ${ }^{23}$.

\section{REPOPULAÇÃO E IMUNIDADE}

É interessante perceber que os parâmetros discutidos acerca da cinética e repopulação tumoral (hipóxia, necrose, $\mathrm{pH}$ ) influenciam, além das células tumorais, a atração de elementos da imunidade e a composição do infiltrado inflamatório. Esses elementos, como visto anteriormente, também influenciarão na repopulação tumoral.

Alguns exemplos já foram apresentados, como a coinoculação de células apoptóticas com células tumorais. Nesse caso, a presença de células em apoptose é capaz de induzir uma resposta imune que promove o crescimento das células tumorais, permitindo o estabelecimento de um tumor. Outro exemplo é a necrose, que, presente em tumores sólidos, é responsável por liberar mediadores que estimulam a infiltração e diferenciação de macrófagos. Estes macrófagos podem atuar tanto no crescimento local do tumor (com remodelação tecidual, angiogênese) quanto na expansão sistêmica do tumor, através da facilitação da invasão e metástase tumoral ${ }^{5,6,7,17}$.

Outro estudo interessante nesse sentido mostra que alguns tumores são capazes de inibir a atuação de células T anti-tumorais através do acúmulo de adenosina extracelular no microambiente tumoral, decorrente da hipóxia local. Além disso, as células $T$ ativadas podem ser inibidas por altos níveis do fator indutível de hipóxia- $1 \alpha$ (hypoxia inducible factor-1 $\alpha$, HIF-1 $\alpha$ ), um fator imunossupressor. O HIF-1 $\alpha$ se torna elevado nas células $T$ devido à sua estabilização pela hipóxia no microambiente tumoral ${ }^{28}$.

\section{CONCLUSÃO}

Esta revisão procurou, inicialmente, expor o câncer em sua atual compreensão. O modelo de tumor como somente um conjunto de células neoplásicas foi percebido pela comunidade científica como insuficiente, e a desmontagem dessa idéia permitiu a reconstrução de um novo conceito de tumor, dessa vez incluindo os elementos do meio em que as células neoplásicas crescem, o chamado microambiente tumoral. A revisão foi focada, então, nos dois principais eixos de estudo deste microambiente, o infiltrado inflamatório e a cinética tumoral. Foram analisados diferentes aspectos do tecido neoplásico, para então, na finalização, mostrar que, sendo parte do mesmo microambiente, esses dois eixos também interagem e se influenciam.

Apesar dessa revisão se focar no aspecto básico da oncologia, é importante colocar que existem vários trabalhos e estudos que estão transformando o conhecimento básico em aplicado. Mais que mudanças de paradigmas e aperfeiçoamento de modelos teóricos, as descobertas que desenham esse novo e complexo conceito de câncer são fundamentais porque permitem o desenvolvimento de novas formas de terapias contra o câncer, além do aprimoramento de tratamentos já existentes. 
Onuchic AC, Chammas R. Câncer e o microambiente tumoral.

Onuchic AC, Chammas R. Cancer and the tumor microenvironment. Rev Med (São Paulo). 2010 jan.-mar.;89(1):21-31.

\begin{abstract}
Formerly referred to as a group of altered cells in proliferation, today cancer is better understood as a microenvironment, in which the interactions between the cellular and molecular elements are determinative in tumor progression. As a result, the comprehension of a neoplasic event gains increasing complexity. The dynamics of the tumor cells are now analyzed as part of a true tumoral tissue, subject to conditions of vascularization, oxygenation, interstitial pressure and tissue necrosis, which influence tumor kinetics. New components of this tumoral niche and their respective actions are being identified. Among these constituents are the elements of the immune system which, as a series of experiments have shown, are involved in the aspect of immunosurveillance, as negative selective pressure, as well as in mechanisms of tumor progression. This review will analyze neoplasia as a tumor microenvironment, focusing on immunological participation and on tumor kinetics, and exposing the main ideas and discoveries that created and are improving the concept of cancer.
\end{abstract}

KEY WORDS: Neoplasms/immunology; Neoplasms/genetics; Inflammation; Immunologic surveillance; Macrophages, Tumor burden/immunology.

\title{
REFERÊNCIAS
}

1. Atkins MB. Cytokine-based therapy and biochemotherapy for advanced melanoma. Clin Cancer Res. 2006;12(7 Suppl.).

2. Berasain C, Castillo J, Perugorria MJ, Latasa MU, Prieto J, Avila MA. Inflammation and liver cancer: new molecular links. Ann N Y Acad Sci. 2009;1155:20621.

3. Brade AM, Tannock IF. Scheduling of radiation and chemotherapy for limited-stage small-cell lung cancer: repopulation as a cause of treatment failure? J Clin Oncol. 2006;24:1020-2.

4. Chen CJ, Kono H, Golenbock D, Reed G, Akira S, Rock KL. Identification of a key pathway required for the sterile inflammatory response triggered by dying cells. Nat Med. 2007;13(7):851-6.

5. Chen R., Alvero A.B., Silasi D. and Mor G. Inflammation, cancer and chemoresistance: taking advantage of the Toll-like receptor signaling pathway. Am J Reprod Immunol. 2007;57:93-107.

6. Condeelis J; Pollard JW. Macrophages: obligate partners for tumour cell migration, invasion and metastasis. Cell. 2006;124:263-6.

7. Correa M, Machado Jr J, Carneiro CRW, Pesquero JB, Bader M, Travassos LR, Chammas R, Jasiulionis MG. Transient inflammatory response induced by apoptotic cells is an important mediator of melanoma cell engraftment and growth. Int J Cancer. 2005;114:35663.

8. Coussens LM, Werb Z. Inflammation and cancer. Nature. 2002;420:860-7.

9. Dunn GP, Old LJ, Schreiber RD. The three Es of cancer immunoediting. Annu Rev Immunol. 2004;22:329-60.

10. duPre SA, Redelman D, Hunter KW Jr. Microenvironment of the murine mammary carcinoma 4T1: endogenous IFN-gamma affects tumor phenotype, growth, and metastasis. Exp Mol Pathol. 2008;85(3):174-88.

11. Fischer C, Jonckx B, Mazzone M, Zacchigna S, Loges S, Pattarini L, et al. Anti-PIGF inhibits growth of VEGF(R)-inhibitor-resistant tumors without affecting healthy Vessels. Cell. 2007;131:463-75.

12. Griffon-Etienne G, Boucher $Y$, Brekken C, Suit HD, Jain RK. Taxane-induced apoptosis decompresses blood vessels and lowers interstitial fluid pressure in solid tumors: clinical implications. Cancer Res. 1999;59:3776-82.

13. Hagemann T, Biswas SK, Lawrence T, Sica A, Lewis CE. Regulation of macrophage function in tumors: the multifaceted role of NF-kappaB. Blood. 2009;113(14):3139-46.

14. Hanahan D, Weinberg RA. The hallmarks of cancer. Cell. 2000;100:57-70.

15. Huxham LA, Kyle AH, Baker JH, Nykilchuk LK, Minchinton Al. Microregional effects of gemcitabine in HCT-116 xenografts. Cancer Res. 2004;64:6537-41.

16. Kim JJ, Tannock IF. Repopulation of cancer cells during therapy: an important cause of treatment failure. Nature. 2005;5:516-25.

17. Lin EY, Nguyen AV, Russell RG, Pollard JW. Colonystimulating factor 1 promotes progression of mammary tumors to malignancy. J Exp Med. 2001;193(6):72740.

18. Lin WW, Karin M. A cytokine-mediated link between innate immunity, inflammation, and cancer. J Clin Invest. 2007;117(5):1175-83.

19. Lodish B, Berk A, Zipursky SL, Matsudaira P, Baltimore D, Darnell J. Molecular cell biology. 5th ed. New York: 
W. H. Freeman; 2004.

20. Mantovani A, Sica A, Allavena P, Garlanda C, Locati $M$. Tumor-associated macrophages and the related myeloid-derived suppressor cells as a paradigm of the diversity of macrophage activation. Hum Immunol. 2009;70(5):325-30.

21. Mumm JB, Oft M. Cytokine-based transformation of immune surveillance into tumor-promoting inflammation. Oncogene. 2008;27:5913-9.

22. Pesquero JB, Araujo RC, Heppenstall PA, Stucky CL, Silva JA Jr, Walther T, et al. Hypoalgesia and altered inflammatory responses in mice lacking kinin B1 receptors. Proc Natl Acad Sci. 2000;97(14):8140-5.

23. Petersen C, Eicheler W, Frömmel A, Krause M, Balschukat S, Zips D, et al. Proliferation and micromilieu during fractionated irradiation of human FaDu squamous cell carcinoma in nude mice. Int $\mathrm{J}$ Radiat Biol. 2003;79(7):469-77.

24. Primeau AJ, Rendon A, Hedley D, Lilge L, Tannock IF. The distribution of the anticancer drug doxorubicin in relation to blood vessels in solid tumors. Clin Cancer Res. 2005;11(24):8782-8.

25. Rakoff-Nahoum S, Medzhitov R. Toll-like receptors and cancer. Nat Rev Cancer. 2009;9(1):57-63.

26. Shankaran V, Ikeda H, Bruce AT, White JM, Swanson PE, Old LJ, et al. IFNgamma and lymphocytes prevent primary tumour development and shape tumour immunogenicity. Nature. 2001;410(6832):1107-11.
27. Sinha P, Clements VK, Ostrand-Rosenberg S. Interleukin-13-regulated M2 macrophages in combination with myeloid suppressor cells block immune surveillance against metastasis. Cancer Res. 2005;65(24):1174351.

28. Sitkovsky MV, Kjaergaard J, Lukashev D, Ohta A. Hypoxia-adenosinergic immunosuppression: tumor protection by $T$ regulatory cells and cancerous tissue hypoxia. Clin Cancer Res. 2008;14(19):5947-52.

29. Stutman O. Tumor development after 3-methylcholanthrene in immunologically deficient athymic-nude mice. Science. 1974;183(124):534-6.

30. Tannock IF. The basic science of oncology. 4th ed. New York: McGraw Hill; 2005.

31. Trédan O, Galmarini CM, Patel K, Tannock IF. Drug resistance and the solid tumor microenvironment. J Natl Cancer Inst. 2007;99:1441-54.

32. Whiteside TL. The tumor microenvironment and its role in promoting tumor growth. Oncogene. 2008;27(45):5904-12.

33. Wyckoff JB, Wang Y, Lin EY, Li J-F, Goswami S, Stanley ER, et al. Direct visualization of macrophagesassisted tumor cell intravasation in mammary tumors. Cancer Res. 2007;67:2649-56.

34. Zitvogel L, Tesniere A, Kroemer G. Cancer despite immunosurveillance: immunoselection and immunosubversion. Nat Rev Immunol. 2006;6(10):715-27. 